\title{
Going Smarter in the Connection of Distributed Generation
}

\author{
Karim L. Anaya ${ }^{1,2}$ and Michael G. Pollitt ${ }^{2}$
}

\begin{abstract}
This study explores and quantifies the benefits of connecting more distributed generation (DG) with and without the use of smart connections in Great Britain. We examine the impacts on different parties (Distribution Network Operators, wider society and generators). As illustration we use a specific case study. Alternative connection scenarios are proposed (with partial and full interruptible capacity quota under a mix of generation with different technology-specific curtailment levels) for integrating DG units in a constrained area of the East of England covered by the Flexible Plug and Play project. The smart (interruptible) connection option is the preferred option across all the scenarios (higher NPV/MW). The analysis of the distribution of benefits between the different parties suggests that generators capture most of the benefits while DNOs and wider society capture much less benefit. A smart connection incentive, which recreates the benefits to DNOs from an earlier losses incentive, is proposed. By contrast with other societally desirable metrics which are usually incentivised or penalised, there is currently no direct connection between more DG MWs connected and DNO incentive payments. Our proposed smart connection incentive, by charging DG for smarter connection may help to distribute more efficiently the benefits for connecting more DG.
\end{abstract}

Key words: distributed generation, renewable energy, smart solutions, cost benefit analysis, smart connection incentive

\footnotetext{
${ }^{1}$ Corresponding author.

${ }^{2}$ The authors are with the Energy Policy Research Group (EPRG) from University of Cambridge, Cambridge, England. (e-mail: k.anaya@jbs.cam.ac.uk; m.pollitt@jbs.cam.ac.uk).
} 


\section{Introduction}

The growth of Distributed Generation (DG) is being influenced by renewable energy targets and related regulation. Diverse incentive and subsidy schemes that benefit renewable generators have been applied in many countries. Electric utilities (which own distribution networks) play an important role by operating and facilitating the connection of more DG units. However, the operation of DG units might be subject to unbundling rules. For instance in the EU, Distribution System Operators (DSOs) are prevented from owning and operating generating units.

The expansion of DG brings benefits to different parties such as DG developers/owners, network utilities and society, but there are also challenges. On the one hand, the incorporation of DG into distribution networks produces important effects on the traditional operation of Distribution Network Operators (DNOs). Existing distribution networks are designed to be passive and to transport electricity from transmission grid off-take points to end customers with minimal levels of control, monitoring and supervision; and were not designed to accommodate generation at lower voltages. On the other hand, DG may have a positive effect across the different parties, not only in terms of technical issues (losses reduction ${ }^{3}$, security of supply, provision of ancillary services) but also in terms of other benefits arising from the use of active networks via innovative (smarter) commercial arrangements.

The paper has two major aims. The first one relates to the evaluation and estimation of the most relevant benefits from facilitating earlier and greater quantities of DG by examining different connection scenarios (with and without smart solutions) applicable to the GB energy market context. A cost-benefit analysis (CBA) methodology is proposed and conducted. The CBA refers to a specific case study (the Flexible Plug and Play project implemented by UK Power Networks). The paper estimates the allocation of these benefits across the different parties (DNOs, generators

\footnotetext{
${ }^{3}$ Based on the British context, this study assumes that power losses are lower when integrating more DG (Passey et al, 2011; Eurelectric, 2013). For high penetration levels of DG the results can be opposite (Quezada et al., 2006; González-Longatt F.M., 2007; NREL, 2016). However, in contrast with the previous work, Cohen and Duncan (2015) find that losses decrease when increasing PV penetration.
} 
and wider society ${ }^{4}$ ). We want to know how each of the parties benefit and to what extent. The second one involves a regulatory proposal that would put in place a better incentive to lead the system agents (i.e. DNOs) to facilitate the right investment. Based on the distribution of these benefits, the authors propose an innovative way that may help to get a more efficient allocation of them: the introduction of a smart connection incentive. This incentive would encourage cheaper and quicker DG connections and would contribute to a more efficient use of the distribution grid infrastructure by reducing unnecessary network reinforcement works (usually borne by end customers). Even though there is a large literature on DG, there is still a gap in the evaluation of the economics of DG that involves not only DG owners/developers/technologies, but also the electric utilities (i.e. DNOs in the UK or DSOs - distribution system operators - in the rest of Europe) and wider society, taking into consideration the specific regulatory context and market arrangements that these are subject to. A brief review of studies that involve economics and benefits of DG suggests that these are concentrated on the benefits for DNOs (including operational improvements, i.e. power losses reduction, ancillary services), DG developers/owners (where benefits are mainly driven by the sale of electricity and at customer level by avoiding wholesale electricity purchase) and benefits related to specific DG technologies (e.g. wind, solar PV, CHP). A summary of some of them is reported in Table 1.

From Table 1 we note that the majority of studies are focused on the benefits for a specific party and this means that an integrated approach is not presented. This is in agreement with Allan et al. (2015) which find that even though there is an extensive DG literature, there are few studies that relate to the pure economics of an individual or group of DG and even less that look at the systemwide impacts of DG. This is explained by the heterogeneous nature of DG which increases the complexity of this kind of evaluation.

\footnotetext{
${ }^{4}$ In this study, wider society is represented by energy suppliers (or demand customers).
} 


\begin{tabular}{|c|c|}
\hline Author(s) & Scope of the paper and findings \\
\hline DEA (2007) & $\begin{array}{l}\text { Evaluates the different benefits of DG by discussing specific case studies applied in the United } \\
\text { States of America. It notes the benefits to electric utilities with a focus on electric system } \\
\text { planning and operations (peak load reduction, ancillary services provision and improvements in } \\
\text { quality of supply). However, the study states that the economics of DG is determined by its very } \\
\text { site-specific characteristics which means that the majority of benefits are easily captured by } \\
\text { customer-owned DG and are greater than those for the utility owned-DG. For instance, through } \\
\text { the implementation of demand side response programs incentives are given to customers- } \\
\text { owned DG for reducing the electricity consumption during peak periods in addition to other } \\
\text { sources of revenue. }\end{array}$ \\
\hline Harrison et al. (2007) & $\begin{array}{l}\text { Explore the trade-offs related to the connection of DG in the UK context. They quantify the } \\
\text { benefits for DNOs and generators taking into account the DG incentives, losses incentives and } \\
\text { network deferral benefits (estimated at } f 250 / \mathrm{kW} \text { ). Using a multi-objective optimal power flow, } \\
\text { they find that the optimal DG capacity to be connected at different locations and the associated } \\
\text { benefits vary between the DNO and generators/developers when benefits from network deferral } \\
\text { are not included. If these are included, the optimal capacity and associated benefits between the } \\
\text { DNOs and generators/developers are quite similar. }\end{array}$ \\
\hline Siano et al. (2009) & $\begin{array}{l}\text { Assess the influence of DG ownership on the economics of DG. Similar to the above study, the } \\
\text { optimal capacity allocation and the respective revenues were determined. Two scenarios are } \\
\text { explored: DNO owning DG and unbundled DNO. They find that the prohibition of DG ownership } \\
\text { limits the DG capacity (and associated revenues) that the DNO may connect (without exceeding } \\
\text { the maximum technically capacity). They suggest that the ownership option may be allowed } \\
\text { under specific operational restrictions (i.e. peak load) in order to limit the revenues for the sale } \\
\text { of electricity. Different ways to deal with the lack of incentives for the DNO (due to the } \\
\text { ownership limitation) are also proposed, by implementing cost reflective charging or tendering } \\
\text { (for bidding capacity). }\end{array}$ \\
\hline $\begin{array}{l}\text { Abou El-Ela et al. } \\
(2010)\end{array}$ & $\begin{array}{l}\text { Estimate the maximum optimal benefits of DG using a multi-objective optimisation technique in } \\
\text { order to optimise more than one objective function simultaneously (composite benefits). The } \\
\text { objective functions are represented by improvements in the voltage profile, increases in spinning } \\
\text { reserve, power flow reduction in critical lines and line-loss reduction. Specific weights are also } \\
\text { used for each function. The authors suggest that siting (bus) and sizing of DG affect importantly } \\
\text { the amount of the objective functions. Results from the composite benefits indicate that DG has } \\
\text { the largest influence on power loss reduction followed by spinning reserve. }\end{array}$ \\
\hline Zangiabadi et al. (2011) & $\begin{array}{l}\text { Explore the economics of customer-owned DG developers using a Monte Carlo based method. } \\
\text { Three different scenarios are assessed, based on the load required per type of customers } \\
\text { (residential, industrial/commercial) and a sensitivity analysis is also conducted with different } \\
\text { electric price scenarios. An award policy is also proposed which represents the extra payment } \\
\text { (above the market electricity price) that a utility would pay to customer-owned DG. This amount } \\
\text { is higher during peak level. Results show important benefits for customer-owned DG developers } \\
\text { and utilities when a suitable power purchase agreement policy is implemented. Customer } \\
\text { benefits are highest when there is production of electricity at times of peak load and the utility } \\
\text { captures the deferment benefit during peak load operation, potentially reducing losses. }\end{array}$ \\
\hline Ben Amor et al. (2012) & $\begin{array}{l}\text { Evaluate the economic value of renewable DG (with a focus on solar PV and micro-wind for } \\
\text { different capacities) in the province of Quebec (Canada) under different climate conditions. The } \\
\text { economic value is estimated by the difference between the life cycle cost and the hourly market } \\
\text { price in four jurisdictions adjacent to Quebec. The evaluation also includes the environmental } \\
\text { benefits related to carbon tax levels and avoided greenhouse gas (GHG) emissions. They find } \\
\text { that DG has no net economic benefits (with or without the internalisation of environmental } \\
\text { benefits) excluding the case of 30kW micro-wind. This fact is mainly explained by the high DG } \\
\text { acquisition costs which makes this market unprofitable in the Northeastern American region. }\end{array}$ \\
\hline Pruitt et al. (2013) & $\begin{array}{l}\text { Evaluate the economic viability of combined heat and power DG by comparing the costs and } \\
\text { savings (including emission savings) of supplying the power and heating demand to commercial } \\
\text { building owners (with and without DG). Eight scenarios are proposed varying the building type } \\
\text { (hotel, office), energy market (California, Wisconsin), and technological system design and } \\
\text { dispatch. The authors find that energy savings are driven by the high electricity to gas price ratio } \\
\text { and market price net metering, and by the use of technologies with greater electric and thermal } \\
\text { efficiencies (e.g. in California). In terms of emission savings, those markets with a higher rate of } \\
\text { carbon emissions (in relation to those from the combustion of natural gas) tend to have higher } \\
\text { savings (e.g. in Wisconsin). The authors find that it is difficult to achieve positive energy savings } \\
\text { and positive emissions savings at the same time. This is mainly explained by the high costs of } \\
\text { low-emitting fuel sources (e.g. gas, nuclear) and the low costs of high-emitting fuel sources (e.g. } \\
\text { coal). }\end{array}$ \\
\hline
\end{tabular}


This paper represents an extension of the findings presented in Anaya and Pollitt (2015a) where only the benefits for distributed generators were estimated. This study explores the distribution of benefits across the different parties taking into account the regulatory context (such as specific incentives provided to DNOs and DG owners in the GB energy market). The study is focused on a constrained area of the East of England (known as the March Grid) operated by UK Power Networks (the largest DNO in the UK). This area has been selected (due to increasing DG) by the DNO to be the trial area of the Flexible Plug and Play (FPP) project, implemented by UK Power Networks. Even though this study is focused on the UK energy market, the method can be easily applied in a different regulatory environment. For instance in the USA, there are different programmes that promote the expansion of $\mathrm{DG}^{5}$. Thus, the type of benefits to be included in the CBA in the USA context (or other) may differ from the one applied in this study.

The paper is organised as follows. Section two discusses the different dimensions of going smarter: smarter technical solutions, smarter commercial arrangements and smarter regulation. Section three describes the methodology for quantifying the benefits of going smarter and shows the results applicable to our case study (relating to the Flexible Plug and Play trial). Section four lays out the conclusions of this study.

\section{The three dimensions for going smarter}

Society is not only concerned about connecting more DG but also about connecting it smartly. Distribution networks have been designed to be passive_with minimal levels of control and network visibility, thus there is a need to get more flexible distribution networks that are able to manage efficiently the integration of renewable (and intermittent) energy sources such as solar and wind

\footnotetext{
${ }^{5}$ There is a mix of federal, state and local regulatory frameworks. Among these are Federal Tax Benefits (FTB), Renewable Energy Certificate (REC) and Solar Renewable Energy Certificate (SREC), production and cost-based incentives, tax credits (in addition to the FTB), net metering, others (NREL, 2015).
} 
power generation and also help to reduce costs to customers by avoiding reinforcement needs ${ }^{6}$. This section explores three dimensions of going smarter with a focus on smart technical tools, smart engagement initiatives and smart regulatory tools. Figure 1 illustrates the dimensions to be discussed.

Figure 1: Going smarter dimensions

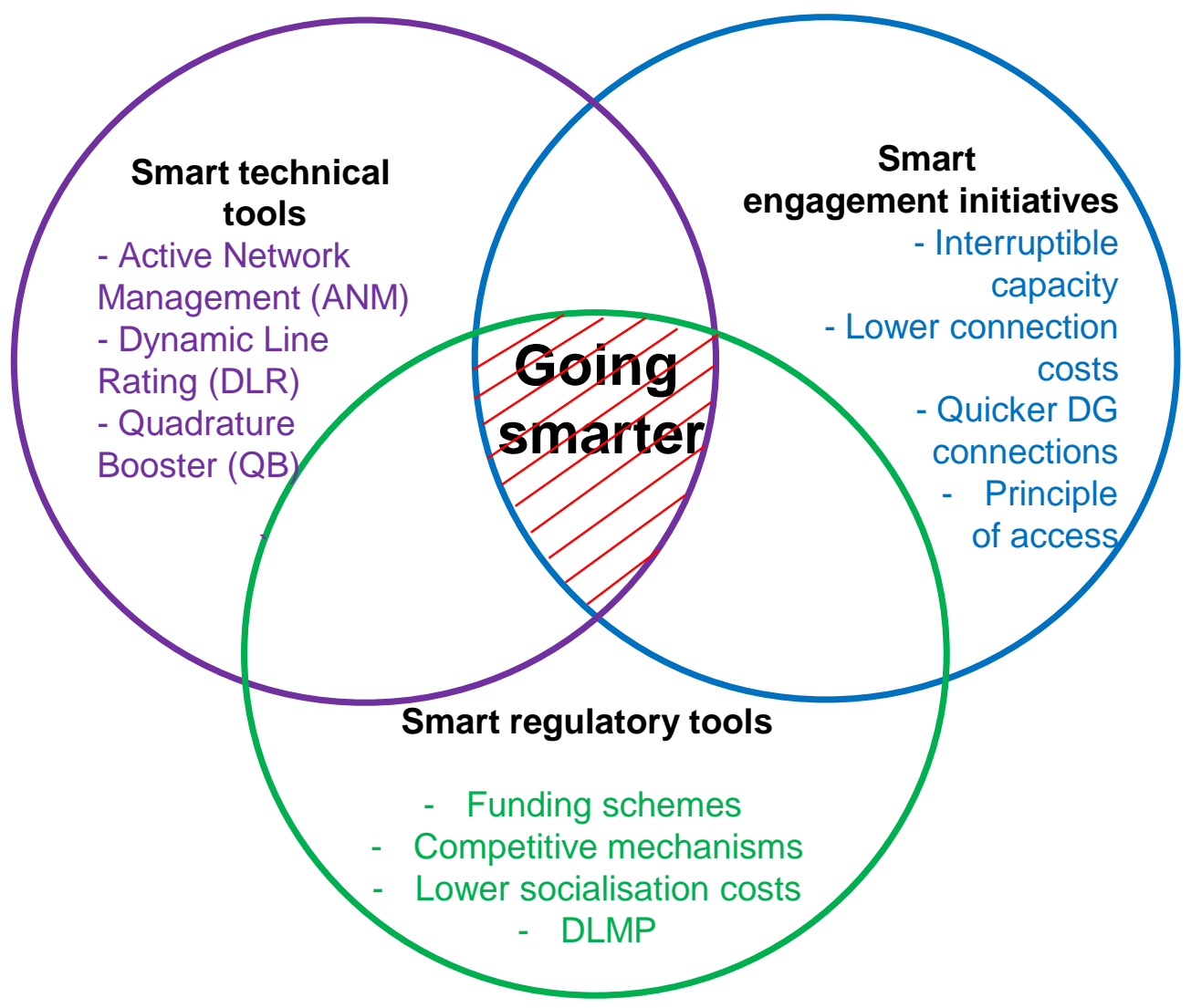

Smart technical tools such as Active Network Management (ANM) integrates different system control components that allow the management of generation and load in real time. ANM also helps to increase the utilization of constrained network assets by reducing the export or import of power flow. The use of ANM has allowed important savings in some initiatives (trials) implemented by distribution network operators in the UK determined by savings in reinforcement needs and by quicker and lower connection costs. Among these are the SEE Power Distribution Orkney project (part of a 'Register Power Zone') where the ANM solution was implemented at

\footnotetext{
${ }^{6}$ According to DECC and OFGEM (2014), the release of existing network capacity by offering flexible connection arrangements (such as smart connections), can help to defer or avoid the need of costly reinforcement of the wider network. In addition, users of flexibility (such as DNOs) can also offer cheaper and quicker connections or manage network issues more appropriately (OFGEM, 2015)
} 
around £0.5m against a conventional reinforcement costs of £30m (Anaya and Pollitt, 2014) and the SP Energy Networks Accelerating Renewable Connections (ARC) project with savings of $£ 6.2 \mathrm{~m}$ at a cost of only $£ 0.8 \mathrm{~m}$ and avoided $£ 20 \mathrm{~m}$ of further worth of reinforcement (House of Commons, 2016). Other projects that have made use of ANM are UK Power Networks Flexible Plug and Play (FPP), Western Power Distribution Lincolnshire Low Carbon Hub (LLCH), Northern Powergrid Customer Led Network Revolution (CLNR), Electricity North West Capacity to Customers (C2C), among others (ENA, 2015). Dynamic Line Rating (DLR) is another smart technology that has usually been linked to the transmission networks, but is now being extended for use in distribution networks. DLR allows the expansion of the distribution capacity limits by measuring actual atmospheric conditions. DLR allows higher dynamic current when possible (instead of the static current which is constrained by assumptions of conventional atmospheric conditions by fixed limits) and at the same time improves safety (ENTSO-E, 2015a). Among the trials in the UK that have used DLR are the FPP and LLCH projects. For instance in the FPP project (where DLR system was installed on $33 \mathrm{kV}$ overhead lines inside the trial area), the average increase in capacity was $14 \%$ higher than the static rating with a peak increase of $47 \%$, in comparison with the summer static rating (UK Power Networks, 2014). Quadrature-booster (QB) is a further smart device that is being trialled to manage constraints and network utilisation. QB is a kind of transformer that helps to balance the power flows across two parallel circuits and creates additional capacity headroom. QB is a mature technology in electricity transmission networks, however its use at distribution is quite innovative. According to UK Power Networks (2015), they have installed (under the context of the FPP project) the first quadrature-booster on the distribution network.

Smart engagement initiatives that allow DG developers to be connected with interruptible capacity are receiving increased attention. DG developers and DNOs are researching different options for connecting more DG in a cheaper and quicker way. OFGEM - through the implementation of the LCNF scheme - aimed to not only test new technologies for facilitating more DG but also smart commercial arrangements. For further details around these arrangements see Anaya and Pollitt 
(2014). Depending on the terms and conditions of the connection agreement, DNOs may internalise the benefits that connecting more DG can provide. For instance, in the case of network constraints, DNOs may offer non-firm (interruptible) connections to generators. This is in contrast to the standard commercial connection contract that guarantees a 'firm' connection, i.e. the capacity to export $100 \%$ of the maximum value of the connection. This involves a restriction on the ability of generators to export power in a constrained part of the network in return for a cheaper connection cost. This will allow the connection of more DG, make a better use of the current infrastructure due to the deferral of network reinforcement, additional DG incentive payments (if applicable) and benefits from losses reduction (to the extent that this effect actually materialises). To ensure this happens, specific commercial arrangements are required ${ }^{7}$. These might involve:

a. the specification of a maximum level of the reduction of the generator output (curtailment);

b. an appropriate principle of access which defines the methodology to limit the generation output in the case of networks constraints (e.g. LIFO, Pro Rata);

c. a capacity quota that sets the maximum capacity reserved for interruptible connections;

d. compensation schemes (if any) in the case of curtailment and different scenarios associated with demand growth;

e. criteria for network reinforcement, and;

f. consideration of the generation mix (e.g. wind, solar PV, and biomass generation plants connected to the same point of connection).

Such commercial arrangements will usually require the implementation of smart technical solutions (i.e. ANM). The practice of novel commercial arrangements is still a work in progress. The challenge that DNOs will face in the short or medium term is to internalise and incorporate such novel commercial arrangements into business as usual practice the offering of commercial arrangements with interruptible connections to potential or existing generators. UK Power

\footnotetext{
${ }^{7}$ UK Power Networks have offered innovative commercial arrangements to DG in the context of the FPP project. The commercial templates can be found at: http://innovation.ukpowernetworks.co.uk/innovation/en/Projects/tier-2-projects/Flexible-Plug-and-Play(FPP)/\#docs
} 
Networks committed to offer this option into its business as usual process by the second quarter of 2015 (UK Power Networks, 2013) . $^{8}$

The use of smart technical tools and smart engagement initiatives is also supported by the use of smart regulatory tools. Looking at different experiences (which also differ among each other), regulation is no longer based on static frameworks. Regulation is evolving over time, in order to promote more flexible networks for integrating more DG (driven by the meeting of renewable targets especially in Europe and USA) and to protect consumers interests by a more efficient cost allocation across customers. Regulation plays an important role in the way that the different parties may internalise the benefits and take advantage of the connection of more DG. Regulation has supported generators through the implementation of different incentives and subsidy schemes for encouraging the deployment of DG. The subsidies are paid by consumers in their respective energy bills. In Great Britain, Feed-in Tariffs (FITs), ROCs (Renewable Obligation Certificates), Levy Exemption Certificates (LECs) and ultimately Contracts for Difference (CfDs) are among the instruments used to support DG. However the sophistication of these schemes has increased over time. Specific bonuses, digression rates (fixed and flexible) and stepped tariff schemes apply depending on the technology (Anaya and Pollitt, 2015b).

Competitive mechanisms for allocating DG capacity are also observed. Based on the latest renewable Energy Act (EEG 2016) in Germany, the FIT scheme (applicable to renewable installations over $750 \mathrm{~kW}$ ) will be replaced by a tendering system from 2017 onwards, with tailored auction designs depending on the renewable technology. There are expected to be between three or four auctions per year and the use of deployment corridors. In 2011, the California Public Utilities Commission launched the Renewable Auction Mechanism (RAM), a simplified marketbased procurement mechanism for projects greater than $3 \mathrm{MW}$ and up to $20 \mathrm{MW}$, with periodic auctions (at least 4, every 2 years). There is a target of $1.3 \mathrm{GW}$ to be connected by the 3 investorowned utilities from California (SCE, SDG\&E, PG\&E). Currently, six auctions have been

\footnotetext{
${ }^{8}$ According to UK Power Networks flexible (or interruptible) connections are being introduced in a phased manner with about $108 \mathrm{MW}$ of operational flexible DG by July 2016. The current areas involved in this deployment are March, Norwich and Peterborough.
} 
performed with total approved contractual capacity of $1.38 \mathrm{GW}$ (from RAM 1 to RAM 5) ${ }^{9}$. Other innovative funding initiatives may encourage DNOs to try out different ways to integrate DG. These may involve support for research, innovation and trials of new technologies and commercial arrangements. In the UK those were represented initially by the Innovation Funding Initiative (IFI) and the Low Carbon Networks Fund (LCNF). Through the introduction of the current RIIO Price control, those mechanisms were replaced by the Electricity Network Innovation Competition (NIC) and the Electricity Network Innovation Allowance (NIA). The NIC allows DNOs to compete for funding for the development and demonstration of new technologies, operating and commercial arrangements. The annual cap for this fund is $£ 81 \mathrm{~m}^{10}$. The NIA allows funding for small projects (technical, commercial or operational) related to the distribution business that are able to get benefits to the DNO and its customers. The NIA also may cover the costs of preparing projects for the NIC.

The current regulatory framework (RIIO-ED1) also proposes important changes that comprise of incentives and mechanisms for DNOs to facilitate the connection of DG to the network more efficiently (smart connections). RIIO-ED1 encourages the provision of good levels of service, efficient investment, appropriate response to demand from DG customers, and the exercise of more innovate alternatives to traditional reinforcement (OFGEM, 2013a). RIIO-ED1 proposes a range of incentives and mechanisms that are part of different outputs. In contrast with the previous price control, RIIO-ED1 DNOs are incentivised $100 \%$ of totex. This allows the equalisation of DNOs incentives between capex and opex promoting better investment decisions. The implementation of low carbon networks can be encouraged in situations when opex rather than capex offers better value for money. The connections that require network upgrades may benefit from this reduction in expenditure on network reinforcement. DNOs are also encouraged to be more efficient due to the increase in their exposure to the expenditure that they have to face. This efficiency can be transferred to DG and DUoS customers by offering cheaper and more innovative connections.

\footnotetext{
${ }^{9}$ See: $\underline{\text { http://www.cpuc.ca.gov/Renewable_Auction_Mechanism/ }}$

${ }^{10}$ In the 2016 NIC Competition, only 7 projects have passed the initial screening process.
} 
Finally, in terms of prices, an innovative way that would provide more value to the distributed energy resources (such as distributed generation) is the implementation of a spatial differentiation of prices: the distribution locational marginal price (DLMP). The introduction of DLMP would enable economically efficient prices that reflect the time and location-specific value of real energy, reactive power and reserves and also would minimise transaction costs associated with the sale/purchase of DER core products (Tabors Caramanis Rudkevich, 2016). Following MIT (2016), the current use of Locational Marginal Prices (LMP) is limited to the transmission nodes and to only some power systems (North/South America and Australia).

The following section quantifies the benefits of DG using smart solutions, using a worked example. We have taken the Flexible Plug and Play project as our case study.

\section{Case Study: Flexible Plug and Play Quantification of Benefits}

This section quantifies the benefits that DNOs, generators and wider society may be entitled to in return for connecting more DG within the distribution grid, in the context of the Flexible Plug and Play project. The introduction of the smart connection incentive is also discussed in this section. The analysis is performed based on the cost benefit analysis (CBA) methodology discussed in Anaya and Pollitt (2015a). Our CBA is provides a comprehensive and systematic framework for evaluating individual/group projects from the perspective of society (Allan et al., 2015). Developers are seeking connections in a constrained part of the network within the trial area in the East of England (March Grid). According to UK Power Networks, as of December 2014, the number of offers accepted to connect to the March Grid was 12 with a total capacity of 27.63 MW. The constrained area is driven by the excessive reverse power that flows on the existing 45 MVA transformers (132/33kV). Only interruptible connections are now possible in this area without any major reinforcement works (i.e. a primary transformer upgrade).Three scenarios have been evaluated in this study as outlined in Table 2 . We have assumed a fixed demand across the project 
lifetime (set at 20 years), a maximum curtailment level for each type of technology (modelled by Smarter Grid Solutions, a project partner), different sizes of installed capacity (from partial to full interruptible capacity quota) and a combination of types of renewable generation technologies (e.g. wind, solar PV and anaerobic digestion (AD) CHP (combined heat and power)).

Table 2: Summary of Scenarios

\begin{tabular}{lcccc}
\hline \multirow{2}{*}{ Scenario } & Installed capacity & \multicolumn{4}{c}{ Generation mix (\% installed capacity) } \\
\cline { 3 - 5 } & (MW) & wind & solar PV & AD CHP \\
\hline Scenario 1 & 14.5 & $100 \%$ & & \\
Scenario 2 & 27.627 & $52.5 \%$ & $43.9 \%$ & $3.6 \%$ \\
Scenario 3 & 33.5 & $60.8 \%$ & $36.2 \%$ & $3.0 \%$ \\
\hline
\end{tabular}

Benefits to DNOs, generators and wider society are estimated in the following sections for each scenario. All figures are expressed in 2014 prices and technology specific discount rates (pre-tax real) have been used for NPV estimations in agreement with the latest generation costs report published by DECC (2013). The actual generation costs are commercially sensitive and not known to the DNO. A project lifetime of 20 years (period 2014-2034) has been assumed regardless of the type of generation plant. The assumptions, formulas and references are shown in Appendix A.

\subsection{DNOs’ Benefits}

These benefits are made up of the DG incentives that DNOs may be entitled to. The DG incentives were introduced in the previous price control review (DPCR4, period 2005-2010).

DG incentives represent a kind of cost-recovery mechanism (or uncertainty mechanism) that contributes to the reduction of uncertainty regarding the volumes of DG connections. Accordingly to OFGEM, the DG incentives help to reduce the risks to DNOs and their customers of bad forecasts of volumes and costs which would have otherwise been part of allowed revenues set ex ante with the rest of the price control. The DG incentives represent the incentive revenues received for connecting DG and are included in the estimation of the total allowed distribution network 
revenue. These incentives apply to all generators, at all voltages. In agreement with Harrison et al. (2007); Siano et al. (2009) and Hung and Mithulananthan (2012); it was assumed that the total benefits arising from the DG incentives are the annual operation and maintenance (O\&M) allowance valued at $£ 1 / \mathrm{kW}$ and the annual DG capacity allowance also valued at $£ 1 / \mathrm{kW}$ in the previous price control (DPCR5, period 2010-2015) (OFGEM, 2009). DNOs benefit from both incentives regardless of the existence of use of system capex. The incentives are valid for 15 years after the date of connection (for this case study is 2014) and need to be inflation adjusted ${ }^{11}$. Total benefits have been calculated for each scenario. Due to the fact that the incentives provided depend only on the installed capacity, different trends are observed across the three scenarios. Figure 2 depicts the annual benefits.

Figure 2: DG Incentives for DNOs, Benefits over time

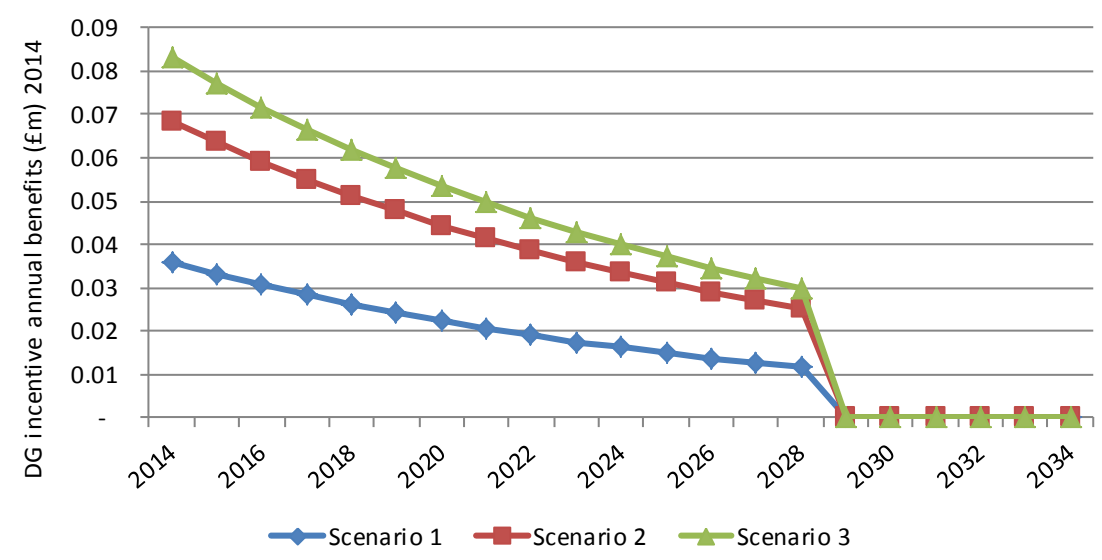

It is noteworthy that under the context of the price control which began on April $1^{\text {st }} 2015$ (RIIOED1, 2015-2023), OFGEM agreed to remove this scheme. This means that DNOs will only benefit from this scheme until 31st March 2015. The principle of grandfathering applies to those connected by that date. Following OFGEM (2013a, b), one of the main reasons for the removal was that the perceived complexity of the scheme was a barrier to the connection of DG. In addition, OFGEM believes that DG incentives are no longer required given the package of measures sets in RIIO-ED1 (OFGEM, 2012). However, the need for more flexible networks that

\footnotetext{
${ }^{11}$ The allowance figures have been adjusted to 2014 prices using the Retail Price Index.
} 
allow a more efficient integration of distributed generation and the implementation of other smarter power initiatives (e.g. energy storage, demand side response, interconnectors) would require the adaption of current energy policies and regulation.

\subsection{Generators’ Benefits}

The generators' benefits are represented by the profits that generators get from connecting DG units (revenues minus costs). These include the energy revenues, the generator share of embedded benefits ${ }^{12}$ and energy savings (for solar PV) ${ }^{13}$. Revenues are composed of the sale of electricity in the wholesale market and of the subsidies and incentives (e.g. FIT, RO, LEC) received by renewable generators. Costs involve generation and connection costs. Generation costs refer to operating and capital expenses associated with electricity generation which vary depending on the kind of technology. Connection costs include those associated with smart or non-firm connections (FPP connection costs) and those associated with the network upgrade when a firm connection is preferred (which includes reinforcement costs) ${ }^{14}$. DG in Great Britain has to pay for the distribution system reinforcement up to the first transformer to which they are connected. This means that to the extent that firm capacity requires additional system reinforcement relative to nonfirm capacity, there will be higher total distribution costs. If a number of generators connect into the same transformer, which needs to be reinforced they will share this additional cost in relation to their capacity.

\footnotetext{
${ }^{12}$ Refer to those costs that generators and suppliers may save when they are directly connected to the distribution network instead of the transmission network. Other jurisdictions may be subject to different rules (ENTSO-E, 2015b). According to the Balancing and Settlement Code (BSC) users of the transmission system (i.e. generators and suppliers) are liable for specific charges in Great Britain under specific splits which depend on the type of charge. Among these are Balancing System Use of System (BSUoS) charges which recover the cost of balancing the system and the system operation function. In our estimation, these charges are net of Residual Cashflow Reallocation Cashflow (RCRC) which represents the payment/charge that is redistributed amongst all Balancing Settlement Code (BSC) parties in proportion to their volume of credit energy. The other one is related to transmission losses (TL). Again, costs related to these losses are allocated among the users of the transmission system, this means between generators and suppliers. Generator transmission losses reduction refers to those charges that generators would pay if they were connected to the transmission network (based on the GB regulatory framework). Suppliers that contract with distributed generators can also benefit from the alleviation of transmission related charges. In line with Baringa - UK Power Networks (2013), in the estimation of those benefits associated with generator transmission losses we have used as reference the wholesale electricity gate price and for those related to the supplier transmission losses the electricity price at the notional balancing point (NBP). Appendix A shows the full list of embedded benefits that have been included in the CBA.

${ }^{13}$ Energy savings refer to those savings that owners of solar PV generators enjoy when the produced electricity is used for own consumption on site. An export rate of $85 \%$ has been assumed. This means that $15 \%$ of the electricity produced is for own consumption. Savings are represented by the cost of electricity that the PV generators would have paid (value at £110 MWh, 2014 prices) if they would have needed to buy this electricity from a supplier using the local distribution company.

${ }^{14}$ FPP connection costs vary by generator, involve smart solutions (e.g. ANM) and include the cost associated with these solutions (£50,000/generator). Reinforcement costs which are represented in this example by the replacement of a specific transformer (with a total cost of $£ 4.1 \mathrm{~m}$ ) have been shared among all the generators connected into the same transformer.
} 
The array of generators for each scenario is the current list of generators (updated to December 2014) that have been connected to the constrained area of March Grid before April 2015. Three connection scenarios are evaluated against a total maximum capacity quota of 33.5 MW. These are: S1 - wind generation only with partial quota (14.5 MW), S2 - a mix of generation technologies with partial quota (27.627 MW) and S3 - a mix of generation technologies with full quota (33.5 MW). The annual curtailment limit varies across the three scenarios. Scenario 3 is the one with the highest level of curtailment limits (more capacity connected), see Table 3.

Table 3: Array of generators for each scenario

\begin{tabular}{|c|c|c|c|c|c|c|c|c|c|c|c|c|}
\hline \multicolumn{3}{|c|}{ Generators } & \multicolumn{2}{|c|}{ Scenario 1 (S1) } & \multicolumn{2}{|c|}{ Scenario 2 (S2) } & \multicolumn{2}{|c|}{ Scenario 3 (S3) } & \multicolumn{4}{|c|}{ Connection costs (2014 prices) } \\
\hline \multirow[t]{2}{*}{ No } & \multirow[b]{2}{*}{ Generators } & \multirow{2}{*}{$\begin{array}{c}\text { Capacity } \\
\text { (MW) }\end{array}$} & \multirow{2}{*}{\begin{tabular}{|c} 
Annual \\
curtailment \\
limit (\%) \\
\end{tabular}} & \multirow{2}{*}{$\begin{array}{l}\text { Estimated } \\
\text { annual } \\
\text { curtailment } \\
\text { MWh }\end{array}$} & \multirow{2}{*}{$\begin{array}{c}\text { Annual } \\
\text { curtailment } \\
\text { limit (\%) }\end{array}$} & \multirow{2}{*}{$\begin{array}{l}\text { Estimated } \\
\text { annual } \\
\text { curtailment } \\
\text { MWh }\end{array}$} & \multirow{2}{*}{$\begin{array}{c}\text { Annual } \\
\text { curtailment } \\
\text { limit (\%) }\end{array}$} & \multirow{2}{*}{$\begin{array}{c}\text { Estimated } \\
\text { annual } \\
\text { curtailment } \\
\text { MWh }\end{array}$} & \multirow{2}{*}{$\begin{array}{l}\text { FPP smarter (non- } \\
\text { firm) connection } \\
\text { costs }^{1 /} \\
(\mathrm{f} \mathrm{m}) \\
\end{array}$} & \multicolumn{3}{|c|}{$\begin{array}{l}\text { Firm connection costs }{ }^{2 /} \\
\qquad(\mathrm{f} \mathrm{m})\end{array}$} \\
\hline & & & & & & & & & & S1 & S2 & S3 \\
\hline 1 & Wind 1 & 0.5 & $0.085 \%$ & 1 & $1.63 \%$ & 21 & $1.84 \%$ & 24 & 0.18 & 0.33 & 0.26 & 0.24 \\
\hline 4 & Wind 4 & 0.5 & $0.085 \%$ & 1 & $1.63 \%$ & 21 & $1.84 \%$ & 24 & 0.13 & 0.28 & 0.21 & 0.19 \\
\hline 5 & Wind 5 & 10 & $0.085 \%$ & 22 & $1.63 \%$ & 428 & $1.84 \%$ & 484 & 0.65 & 3.63 & 2.21 & 1.94 \\
\hline 6 & Wind 6 & 0.5 & $0.085 \%$ & 1 & $1.63 \%$ & 21 & $1.84 \%$ & 24 & 0.24 & 0.39 & 0.32 & 0.30 \\
\hline 7 & Wind 7 & 0.5 & $0.085 \%$ & 1 & $1.63 \%$ & 21 & $1.84 \%$ & 24 & 0.14 & 0.29 & 0.22 & 0.21 \\
\hline 8 & Solar PV 1 & 4 & & & $2.15 \%$ & 84 & $2.30 \%$ & 90 & 0.21 & & 0.84 & 0.73 \\
\hline 13 & Wind 8 & 5.873 & & & & & $1.84 \%$ & 284 & 0.29 & & & 1.04 \\
\hline
\end{tabular}

${ }^{1 / T}$ The cost of the ANM equipment (estimated in $f 50,000 /$ senerator) has been included in these costs.

${ }^{2 /}$ Include reinforcement costs.

The results from the CBA (shown in Figure $3^{15}$ ) suggest that across the three scenarios, the smart connection option is the one preferred by all generators regardless of their size and type of technology. This fact can be explained by the low rates of annual curtailment that generators are subject to, especially in Scenario 1 when less than 50\% of total interruptible capacity quota has been allocated to wind generators only. We also observe that the results are very sensitive to the discount rate used in the analysis.

\footnotetext{
${ }^{15}$ The results from Scenario 3 do not include the potential revenues that AD CHP would receive for heat under the non-domestic Renewable Heat Incentive (RHI). Assuming a production of 520 KWth (based on the estimations made by the 0.5 MW AD CHP1), the NPV of the additional revenue over the project lifetime would be around $£ 0.22 \mathrm{~m}$. This amount would represent approximately $26.6 \%$ and $28.2 \%$ of the NPV of the total revenue regarding AD CHP1 and AD CHP2 respectively. In agreement with DECC (2014), a capacity factor of $13.7 \%$ has been assumed for this calculation.
} 
Figure 3: CBA Results - Generator Net Benefits including embedded benefits

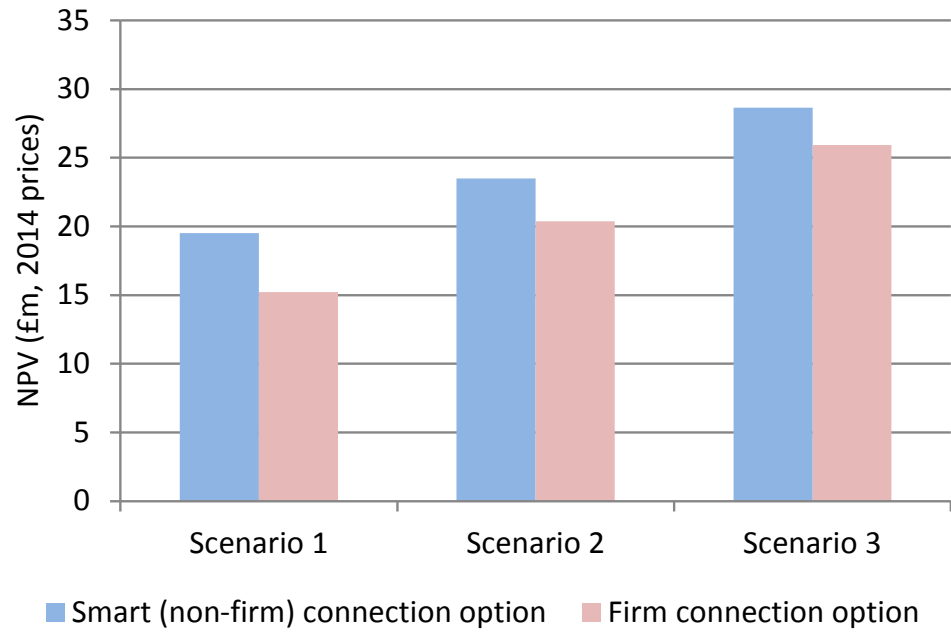

\subsection{Wider Societal Benefits}

These are composed solely of the supplier embedded benefits, because we assume that all the benefits to wider society of the connection of more DG (including reduced carbon emissions) are already reflected in the subsidies that are paid to DG.

Following Baringa-UK Power Networks (2013), embedded benefits are related to the benefits associated with the supplier avoidance of balancing system charges, supplier transmission loss reduction and distribution line losses. The respective formulas for the estimation of the supplier embedded benefits are found in Appendix A. Figure 4 illustrates the NPV of the supply embedded benefits for the smart connection option. We observe that the supply embedded benefits represent on average around $51 \%$ of the total embedded benefits (composed of generation and supply embedded benefits). 
Figure 4: NPV of total and supply embedded benefits

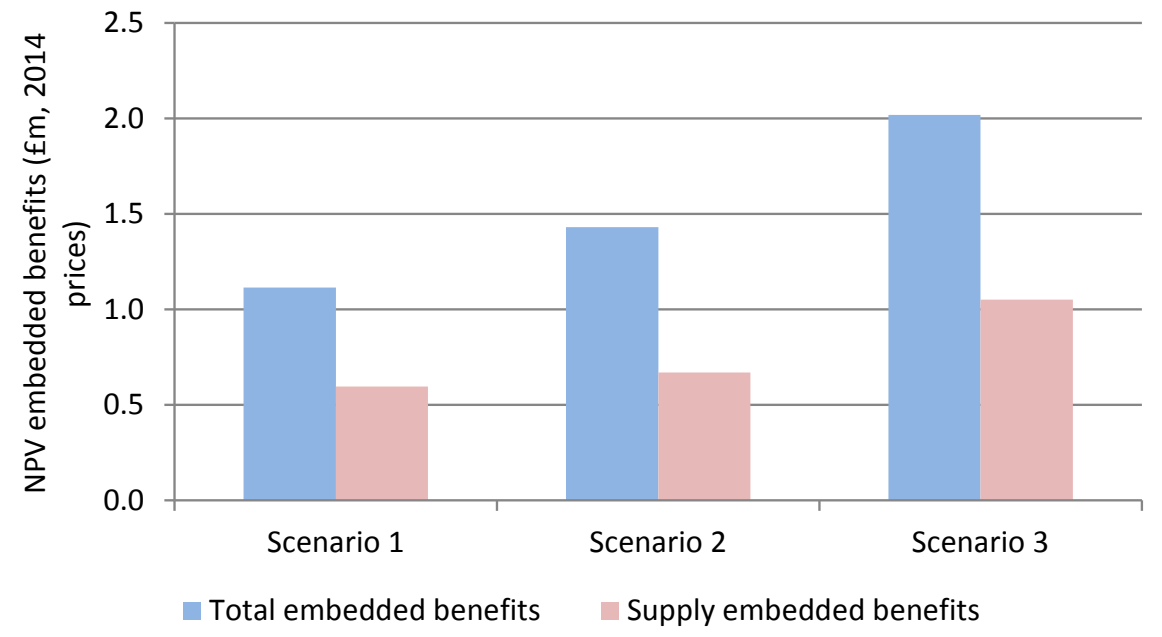

\subsection{Smart Connection Incentive}

Comparison of the benefits from the previous results in sections $3.1-3.3$ suggests that generators are those that benefit the most and wider society the least. Thus, we propose the introduction of a smart connection incentive which recreates the benefits from an earlier losses incentive (removed in 2012) ${ }^{16}$ and may help to rebalance the allocation of benefits across the parties. The smart connection incentive, to be paid by generators to the DNO, would also encourage the expansion of DG connections using smart solutions. This is also in line with Vogel (2009) who suggests that DSOs should get the right incentives to promote the expansion of DG (correct investment signals).

Therefore, we would need to quantify first the benefits from losses reduction (MWh) in order to estimate the smart connection incentive. As mentioned in Section 2, different studies have evaluated the impact that DG has on electric losses. Most of them have made specific assumptions regarding DG penetration, generation load factor, generation mix, voltage limits, network load, among others. Similarly, different techniques have been applied, such as those based on computational algorithms (Mendez et al., 2006; Siano et al. 2009). For our estimations we are going to use a different approach based on the losses associated with the different voltage levels

\footnotetext{
${ }^{16}$ Even though general losses incentives have been removed, OFGEM is committed to continue with the incentives for losses reduction in the upcoming price control period 2015-2023 (RIIO-ED1). Around £32m in losses incentive is expected to be awarded in three tranches over the eight years; up to $£ 8 \mathrm{~m}$ in year 2, up to $£ 10 \mathrm{~m}$ in year four and up to $£ 14 \mathrm{~m}$ in year six (OFGEM, 2013a).
} 
that DG can connect to. The contribution (in percentage terms) of the total distribution losses per voltage level is taken into consideration for estimating the reduction of electric losses due to the connection of DG units at $11 \mathrm{kV}$ and $33 \mathrm{kV}$. Thus, we are assuming that DG will contribute to system losses reduction and that there is a low chance that the injection of power exceeds the local demand. Following OFGEM (2003), the share of losses across different voltage levels is around $19 \%(132 \mathrm{kV}), 14 \%(33 \mathrm{kV}), 34 \%(11 \mathrm{kV})$ and $34 \%$ (LV, including meters). Thus, if a generator is connected at $33 \mathrm{kV}$, electric losses savings would be around 19\% of the average distribution losses. If this is connected at $11 \mathrm{kV}$, savings would be in the order of $33 \%(19 \%+14 \%)$. Table 4 shows the list of generators for each scenario and their respective installed capacity and associated voltage connection level.

Table 4: Summary of DG connections for each scenario

\begin{tabular}{|c|c|c|c|c|c|c|}
\hline \multirow[t]{2}{*}{ Generator } & \multirow{2}{*}{$\begin{array}{c}\text { Installed capacity } \\
\text { (MW) }\end{array}$} & \multirow{2}{*}{\multicolumn{3}{|c|}{ Scenario 1 Scenario 2 Scenario 3}} & \multicolumn{2}{|c|}{ Voltage } \\
\hline & & & & & $33 \mathrm{kV}$ & $11 \mathrm{kV}$ \\
\hline Wind 1 & 0.5 & $\mathrm{x}$ & $x$ & $\mathrm{x}$ & & - \\
\hline Wind 2 & 1 & $x$ & $x$ & $x$ & & • \\
\hline Wind 3 & 1.5 & $x$ & $x$ & $x$ & & • \\
\hline Wind 4 & 0.5 & $x$ & $x$ & $x$ & & • \\
\hline Wind 5 & 10 & $x$ & $x$ & $x$ & - & \\
\hline Wind 6 & 0.5 & $x$ & $x$ & $x$ & & • \\
\hline Wind 7 & 0.5 & $x$ & $x$ & $x$ & & - \\
\hline Solar PV1 & 4 & & $x$ & $x$ & - & \\
\hline Solar PV2 & 6.9 & & $x$ & $x$ & - & \\
\hline Solar PV3 & 1.2 & & $x$ & $x$ & & - \\
\hline AD CHP 1 & 0.5 & & $x$ & $x$ & & • \\
\hline AD CHP 2 & 0.5 & & $x$ & $x$ & & - \\
\hline Wind 8 & 5.8 & & & $x$ & - & \\
\hline \multicolumn{2}{|l|}{ Total (MW) } & 14.5 & 27.6 & 33.5 & & \\
\hline
\end{tabular}

We have assumed that the initial target loss level is equal to the average distribution losses (period 2005/06-2009/10) estimated at 4.89\% for UKPN Eastern Power Networks (EPN). Losses have been calculated on an annual basis for each generator at their respective voltage level. For example, Wind 1 (Scenario 1) generates around 1,310 MWh per year, the target annual losses would be 64.05 MWh (1,310*4.89\%), thus losses reduction are of the order of 21.13 MWh $(64.05 * 33 \%$ @ $11 \mathrm{kV})$. The same procedure is applied to the rest of generators with non-firm and firm connections across the three scenarios. In order to calculate the monetary savings of losses reduction, we have 
value losses at $£ 48.42 / M W h$ (2012/13 prices). This is in agreement with the value assumed by OFGEM in the CBA modelling for RIIO-ED1. It has been also assumed that this value remains the same (in real values) for the whole project lifetime.

Starting from the above, we calculate that the smart connection incentive would take the following values: £15,850/MW (Scenario 1), £12,360/MW (Scenario 2) and £12,395/MW (Scenario 3), with an average value of $£ 13,535 / \mathrm{MW}$. These figures are calculated dividing the NPV of the losses savings over the project lifetime by the installed capacity (related to each scenario).

In order to look at how reasonable this incentive is, we have compared this figure with the savings (applicable to generators) due to deferral of investment based on the year when the network upgrade is made $(t+1, \ldots, t+20)$. UK Power Networks have estimated a gross upgrade cost of $£ 4.1 \mathrm{~m}$ (2012 prices) which mainly reflects those costs associated with the replacement of specific transformers that will allow the increase of the system capacity related to the March Grid constrained area up to 90 MW. However, UK Power Networks has pointed out that the related network reinforcement costs should be incurred by the generators because they have not been budgeted and are not part of the DNO's allowed revenues. Thus, we find it convenient to use the value of $£ 4.1 \mathrm{~m}$ as a reference for computing the benefits due to network deferral but applicable to generators. In fact, the expected investment by the generator in such a system upgrade can be postponed for months or years, thus the estimation of benefits are related to the value of this investment over time.

Benefits from network deferral are estimated by the difference between the gross value of the network investment at present time and the gross present value of the deferred investment at specific year. See the following equation.

$$
\text { Benefits }\left(t_{i}\right)=N I *\left(1-\frac{1}{e^{\delta * t_{i}}}\right) \quad \text { Eq. (1) }
$$


Where NI is the total network investment $(£ 4.1 \mathrm{~m}), \delta$ is the annual discount rate $(5.7 \%)^{17}, \mathrm{t}_{i}$ represents the time of investment deferral (in years) from $\mathrm{i}=1$ to 20 . It has been assumed that the project lifetime is 20 years.

Taking into consideration the different network deferral scenarios suggested in this study, the smart connection incentive may represent between 8\% (Scenario 1, $\mathrm{t}+20$ ) and 178\% (Scenario 3, $\mathrm{t}+1$ ) of total savings due to network investment deferral. The lowest rate corresponds to investment deferral of 20 years while the highest rate relates to an investment deferral of only 1 year. Figure 5 illustrates this dynamic.

Figure 5: Smart connection incentive as percentage of total savings for network investment deferral

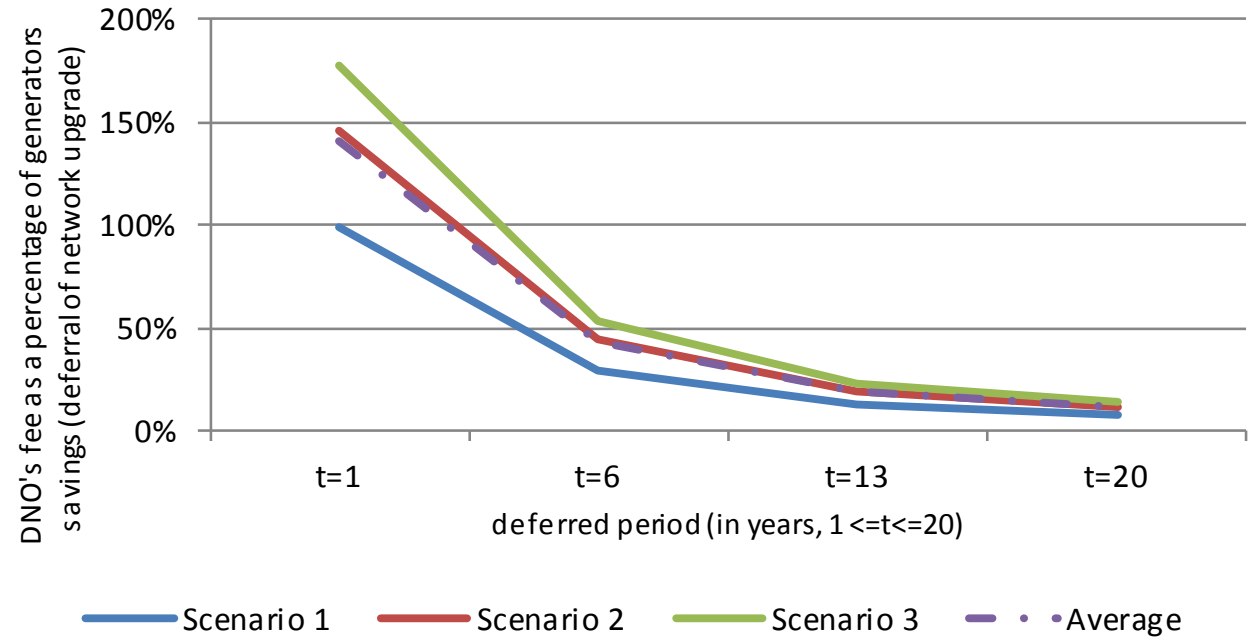

Figure 5 suggests that the proposed incentive, to the extent that it defers network investment by one or more years, is if anything less than the value of the deferral of the network reinforcement expenditure. This suggests that it is of reasonable magnitude.

\subsection{Summary and Discussion of Benefits}

The summary of benefits, including the allocation of these across the different parties, is shown in Table 5.

\footnotetext{
${ }^{17}$ This represents the pre-tax WACC applicable to DNOs.
} 
Table 5: Total benefits under smart connection

\begin{tabular}{|c|c|c|c|c|c|}
\hline Parties & Type of benefit $(\mathrm{fm})^{1 /}$ & Unit & S1 & S2 & S3 \\
\hline \multirow[t]{3}{*}{ DG owners } & $\begin{array}{l}\text { Non-firm connections (going } \\
\text { smarter) }\end{array}$ & $\mathrm{fm}$ & 19.00 & 22.73 & 27.68 \\
\hline & Embedded benefits (generators) & $\mathrm{fm}$ & 0.52 & 0.76 & 0.97 \\
\hline & (-) Smart connection incentive & $\mathrm{fm}$ & -0.23 & -0.34 & -0.42 \\
\hline \multirow[t]{2}{*}{ DNO } & DG incentives & $\mathrm{fm}$ & 0.38 & 0.77 & 0.92 \\
\hline & Smart connection incentive & $\mathrm{fm}$ & 0.23 & 0.34 & 0.42 \\
\hline \multirow[t]{2}{*}{ Wider society } & Embedded benefits (suppliers) & $\mathrm{fm}$ & 0.60 & 0.67 & 1.05 \\
\hline & (-) DG incentives & $\mathrm{fm}$ & -0.38 & -0.77 & -0.92 \\
\hline Total & & $\mathrm{fm}$ & 20.11 & 24.16 & 29.70 \\
\hline benefits & & $\mathrm{fm} / \mathrm{MW}$ & 1.39 & 0.87 & 0.89 \\
\hline
\end{tabular}

The figures refer only to the non-firm connection option because this is the only one that relates to a smart connection (under the firm connection option, generators export 100\% of their electricity and there is no need to manage the generation output actively). It is observed that DNOs and wider society benefit the least and generators the most. Under the current price control review (RIIOED1) there are no specific initiatives that promote and encourage DNOs to connect more DG units within their networks (OFGEM, 2013a). By contrast with other metrics which are usually incentivised/penalised (e.g. Incentive on Connection Engagement - ICE, Guaranteed Standards of Performance - GSOP), there is no direction connection between more MWs and incentive payments. Furthermore, an increase in DG connections, especially those that would require network reinforcement, may affect negatively non-DG customers if these costs need to be socialised. The network upgrade will benefit not only the DNO but also the DG owners; however demand customers will pay for this ${ }^{18}$. These demand customers do not benefit if performance is rewarded generously by them.

From Table 5, we observe that wider society is actually worse off in Scenario 2 and 3 because of the DG incentive payments. This makes a stronger case for charging DG a smart connection fee rather than having an incentive payment paid by DNO customers.

\footnotetext{
${ }^{18}$ If the network reinforcement produces a global impact (i.e. at the level of system optimisation) for the distribution network, it makes sense to share the costs among all the grid users (cost is passed through the customers' bills). However if the network reinforcement provides only a locational value (to the specific area where DG owners will connect), the cost socialisation among all the grid users may not be justified.
} 


\section{Conclusions}

This paper explores the different dimensions of going smarter in the promotion of distributed generation. The case study evaluated in this paper refers to the Flexible Plug and Play trial conducted by UK Power Networks in the March Grid constrained area. The paper analyses and quantifies the opportunities that different parties - namely the DNOs, generators and wider society - have when connecting more DG within the distribution grid.

Different kinds of benefits have been identified and allocated across the parties. Electricity generation benefits are those with the highest proportion of the total benefits. This means that distributed generators are those that benefit the most when the smart connection option is selected. Our results suggest that the introduction of a smart connection incentive payable by generators to DNOs may help to allocate more efficiently the distribution of the benefits from connecting more DG capacity units. The smart connection incentive we propose may also contribute to the reduction of network upgrade or reinforcement costs which usually are borne by customers. This is particularly true especially in areas with a low penetration of DG, as in Great Britain. A high rate of DG penetration may change this result due to the potential increase in energy losses and surplus generation.

Overall, this study shows the existence of potential monetary benefits to DNOs due to the implementation of DG under a new business as usual DG smart connection regime. In addition, this study has quantified the benefits that similar projects may transfer to wider society. We are aware that incentives/subsidies paid by wider society are more than their direct financial benefits, but reflect learning benefits of strategic deployment and cost of achieving the EU renewables target. 
The methodology proposed in this paper for the estimation of benefits can be broadly applicable in similar contexts. However, we note that the CBA methodology does not reflect a full social CBA. Social discount rates and full economic costs would need to be included.

\section{Acknowledgments}

The authors wish to acknowledge the financial support of UK Power Networks via the Low Carbon Networks Fund's Flexible Plug and Play Project (Project agreement ref: 12-00077) and of an anonymous reviewer. The authors are also grateful to Laura Hannant and Sotiris Georgiopoulus from UK Power Networks, and to Smarter Grid Solutions for the provision of relevant information and clarifications. The views expressed herein are those of the authors and do not reflect the views of the EPRG or any other organisation that is also involved in the Flexible Plug and Play Low Carbon Networks (FPP) project. EPSRC data statement: there is no data beyond that reported in the paper. 


\section{References}

Abou El-Ela, A.A., Allam, S.M., Shatla, M. (2010), “Maximal optimal benefits of distributed generation using genetic algorithms”, Electric Power System Research, Vol. 80, pp. 869-877.

Allan, G., Eromenko, I., Gilmartin, M., Kockar, I., McGregor, P. (2015), “The economics of distributed generation: A literature review”, Renewable and Sustainable Energy Reviews, Vol. 42, pp. 543-556.

Anaya, K. and Pollitt, M.G. (2014), “Experience with smarter commercial arrangements for distributed wind generation”, Energy Policy, Vol. 71, pp. 52-62.

Anaya, K. and Pollitt, M.G. (2015a), “Options for allocating and releasing distribution system capacity: Deciding between interruptible connections and firm DG connections”, Applied Energy, Vol. 144, pp. 96-105.

Anaya, K. and Pollitt, M.G. (2015b), “Integrating Distributed Generation: Regulation and Trends in Three Leading Countries”, Energy Policy, Vol. 85, issue C, pp. 475-486.

Baringa - UK Power Networks (2013), Flexible Plug and Play: Reinforcement quota calculation for March Grid, Baringa Partners and UK Power Networks, London.

Ben Amor, M., Pineau, P-O, Gaudreault, C., Samson, R. (2012),”Assessing the economic value of renewable distributed generation in the Northeastern American market”, Renewable and Sustainable Energy Reviews, Vol. 16, pp. 5687-5695.

Cohen, M.A., and Callaway, Duncan S. (2015), Physical Effects of Distributed PV Generation on California's Distribution System, Energy and Resources Group, University of California, Berkeley.

DEA (2007), The potential benefits of distributed generation and rate-related issues that may impede their expansion. A study pursuant to Section 1817 of the Energy Policy Act of 2005, U.S. Department of Energy, Washington DC.

DECC (2011), Consultation on proposal for the levels of banded support under the Renewables Obligation for the period 2013-17 and the Renewables Obligation Order 2012, Department of Energy and Climate Change, London.

DECC (2013), Electricity Generation Costs (December 2013), Department of Energy and Climate Change, London.

DECC (2014), Monthly forecast for the non-domestic RHI scheme as at 30 November 2014, Department of Energy and Climate Change, London.

DECC and OFGEM (2014), Smart Grid Vision and Routemap. Smart Grid Forum, Department of Energy and Climate Change, Office of Gas and Electricity Markets, London.

Elexon (2013), Transmission Losses. Guidance, ELEXON, London.

ENA (2015), Active Network Management. New Practice Guide. Energy Networks Association. 
ENTSO-E (2015a), Dynamic Line Rating for overhead lines - V6. CE TSOs current practice. RGCE SPD WG, European Network of Transmission System Operators for Electricity, Brussels.

ENTSO-E (2015b), Overview of Transmission Tariffs in Europe: Synthesis 2015, European Network of Transmission System Operators for Electricity, Brussels.

Eurelectric (2013), Active distribution system management: A key tool for the smooth integration of distributed generation. Full discussion paper, The Union of the Electricity Industry, Belgium.

Gil, H.A. and Joos, G. (2006), “On the quantification of the network capacity deferral value of distributed generation”, IEEE Trans. Power Syst., Vol. 21, No. 4, pp. 1592-1599.

Gonzáles-Longatt, F.M. (2007), Impact of distributed generation over power losses on distribution systems, paper presented at the $9^{\text {th }}$ International Conference on Electrical Power Quality and Utilization, 9-11. October 2007, Barcelona.

Harrison, G.P., Piccolo, A., Siano, P., Wallace, R. (2007), “Exploring the tradeoffs between incentives for distributed generation developers and DNOs”, IEEE Trans. Power Syst., Vol. 22, No. 2, pp. 821-828.

House of Commons (2016), Low Carbon Network Infrastructure. First Report of Session 2016-17. House of Commons Energy and Climate Change Committee, London.

Hung, D.Q. and Mithulananthan, N. (2012), A simple approach for distributed generation integration considering benefits for DNOs, Presented at 2012 IEEE International Conference of Power System Technology (POWERCON).

Mendez, V.H., Rivier, J. and Gomez, T. (2006), “Assessment of energy distribution losses for increasing penetration of distributed generation”, IEEE Trans. Power Syst., Vol. 21, No. 2, pp. 533-540.

MIT (2016), Utility of the future. An MIT energy initiative response to an industry in transition, MIT Energy Initiative, Massachusetts Institute of Technology, Cambridge, MA.

NREL (2015), Historical and current U.S. strategies for boosting distributed Generation, Technical Report NREL/TP-6A20-64843, National Renewable Energy Laboratory, Denver, CO.

NREL (2016), High Penetration PV Integration Handbook for Distribution Engineers, Technical Report NREL/TP-5D00-63114, National Renewable Energy Laboratory, Denver, CO.

OFGEM (2003), Electricity distribution losses. A Consultation document. January 2003, Office of Gas and Electricity Markets, London. OFGEM (2009), Electricity distribution price control review. Final proposal - Incentives and Obligations, Office of Gas and Electricity Markets, London.

OFGEM (2012), Strategy consultation for the RIIO-ED1 electricity distribution price control: Overview, Office of Gas and Electricity Markets, London. 
OFGEM (2013a), Strategy decision for the RIIO-ED1 electricity distribution price control. Outputs, incentives and innovation. Supplementary annex to RIIO-ED1 overview paper, Office of Gas and Electricity Markets, London.

OFGEM (2013b), Renewables Obligation: Guidance for Generators, OFGEM E-Serve, Office of Gas and Electricity Markets, London.

OFGEM (2015), Making the electricity system more flexible and delivering the benefits for consumers. Position paper, Office of Gas and Electricity Markets, London.

Passey, R., Spooner, T., MacGill, I., Watt, M. and Syngellakis, K. (2011),’The potential impacts of grid-connected distributed generation and how to address them: A review of technical and non-technical factors”, Energy Policy, Vol. 39, No. 10, pp. 6280-6290.

Pöyry (2013), Potential impact of revised Renewables Obligation technology bands: updated modelling, Pöyry Management

Consultancy, Oxford.

Pruitt, K.A., Braun, R.J., Newman, A.M. (2013),’Establishing conditions for the economic viability of fuel-cell-based, combined heat and power distributed generation systems”, Applied Energy, Vol. 111, pp. 904-920.

Quezada, V.M., Abbad, J.R., Roman, T.G.S. (2006), “Assessment of energy distribution losses for increasing penetration of distributed generation”, IEEE Trans. Power Syst. 21(2), pp. 533-540.

Siano, P., Ochoa, L.F., Harrison, G.P., Piccolo, A. (2009), “Assessing the strategic benefits of distributed generation ownership for DNOs”, IET Gener. Transm. Distrib., Vol. 3, No. 3, pp. 225-236.

Tabors Caramanis Rudkevich (2016), Valuing distributed energy resources (DR) via Distribution Locational Marginal Prices (DLMP), PJM Annual Meeting, Boston, MA.

UK Power Networks (2013), Business Plan (2015-2023) Core Narrative, UK Power Networks, London.

UK Power Networks (2014), Dynamic Line Rating Trial Report, UK Power Networks, London.

UK Power Networks (2015), Quadrature-booster Trial and Learning Report, UK Power Networks, London.

Vogel, P. (2009), “Efficient investment signals for distributed generation”, Energy Policy, Vol. 37, pp. $3665-3672$.

Zangiabadi, M., Feuillet, R., Lesani, H., Hadj-Said, N., Kvaloy, Jan T. (2011), “Assessing the performance and benefits of customer distributed generation developers under uncertainties”, Energy, Vol. 36, pp. 1703-1712. 


\section{Appendix A}

\section{List of variables, formulas and references}

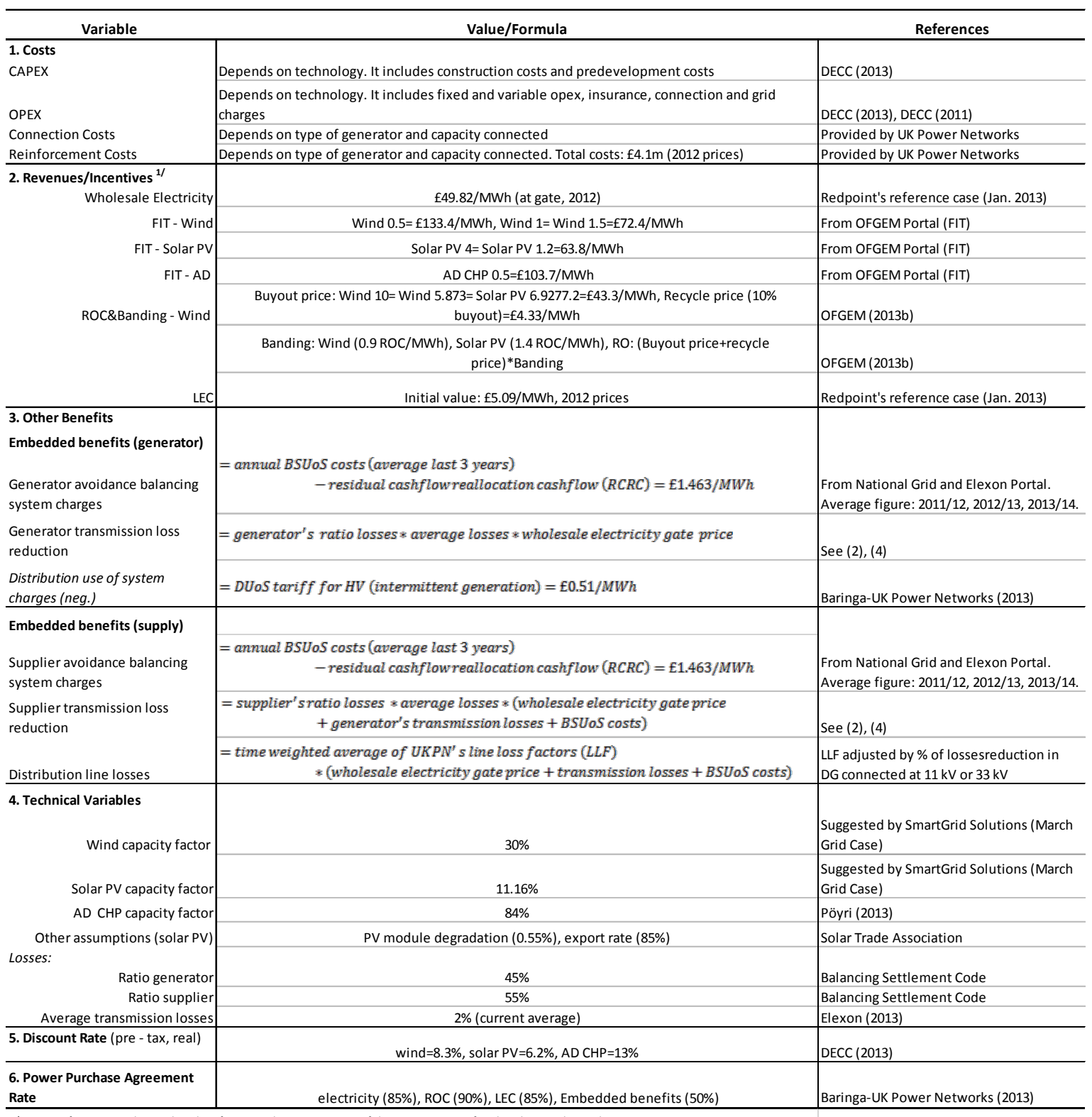

